\title{
Who Becomes an Entrepreneur? How Changes In Activity Systems Affect Entrepreneurial Action
}

$\underline{\text { Authors }}$

Rognvaldur J Saemundsson, U. of Iceland, rjs@hi.is

Magnus Holmén, Halmstad U., magnus.holmen@hh.se 
Submission \#16318

\title{
Who Becomes an Entrepreneur? How Changes In Activity Systems Affect Entrepreneurial Action
}

\begin{abstract}
Entrepreneurs create and appropriate value by designing a system of interconnected and interdependent activities that determine how they do business. These activity systems span beyond the individual firm and compose complex interconnected ecosystems. Current research focuses on how entrepreneurs design new activity systems but do not focus on how these changes create new entrepreneurial opportunities and for whom. In this paper we ask why some people but not others pursue entrepreneurial opportunities following changes in an activity system. Based on Lachmann's theory of capital we develop a theoretical framework for analyzing how changes in the structure of activities affect the knowledge required to pursue subsequent entrepreneurial opportunities.
\end{abstract}

\section{INTRODUCTION}

In his early work Joseph Schumpeter (1934) focused on the role of the entrepreneur in changing the economy from within. He argued that entrepreneurs create new value through innovation by changing the structure of the economy in a fundamental way. Initially, the entrepreneur will be able to appropriate a large share of this value but with time profit will be eroded by imitation. From this follows that an entrepreneur who wants to continue to profit must continue to innovate, suggesting an endogenous process of economic growth and development.

Two important qualifications have been made to Schumpeter's model based on historical studies of technological innovation (Rosenberg 1976, 1982). First, the innovation process is rarely characterized by instantaneous breakthrough and discontinuity but is typically a time consuming 
process composed of many small steps before an invention or an idea becomes commercially viable. Second, what Schumpeter terms as imitation is seldom a mere reproduction but rather includes creative adaptations and improvements on par with the steps that precede it. Seen from this perspective the Schumpeterian process of economic growth and development is a continuous and evolutionary process where entrepreneurial action will change the structure of the economy, and these changes will in turn create new opportunities for entrepreneurial action (Buensdorf 2007).

Traditionally, entrepreneurship research has not focused on this endogenous nature of entrepreneurship. Early on entrepreneurship scholars searched for personal traits that could provide answers to the question who becomes an entrepreneur (cf Brockhaus and Horwitz 1986), but as the results from this search turned out to be inconclusive attention has shifted towards understanding how the interaction between enterprising individuals and available opportunities triggers and shapes entrepreneurial action, i.e. why, when, and how some people and not others identify and exploit entrepreneurial opportunities (Shane and Venkataraman 2000). This shift has generated a stream of research investigating the nature of entrepreneurial opportunities (Alvarez and Barney 2007; Eckhardt and Shane 2003; Sarason, Dean, and Dillard 2006; Sarasvathy, Drew, Velamuri, and Venkataraman 2003, Short, Ketchen, Shook, and Ierland 2010) and the characteristics of the opportunity process (Ardichvili, Cardozo, and Ray 2003; Barreto 2012; Choi and Shepherd 2004; Dimov 2007; Gaglio 2004; Haynie, Shepherd, and McMullen 2009; Mitchell, Mitchell, and Smith 2008; Shepherd, McMullen, and Jennings 2007).

Recently, a stream of research has become interested in how entrepreneurs create and appropriate value by designing systems of interconnected and interdependent activities that determine how they do business (Zott and Amit 2010; Zott, Amit and Massa 2011). These activity systems span 
beyond the individual firm and compose complex interconnected ecosystems (Adner and Kapoor 2010). This research provides a language for describing how entrepreneurs change the economic structure by designing their activity systems but does not address how these changes create new opportunities for entrepreneurial action and for whom.

The purpose of this paper is to help fill this gap. We ask why some people, but not others, pursue entrepreneurial opportunities following changes in an activity system. We base our analysis on Lachmann's (1956/1978) theory of capital and Menger's (1871/1976) original work on goods of different order to connect development of knowledge, entrepreneurial action and qualitative changes in the capital structure of the economy. We develop a theoretical framework for analyzing how changes in the structure of activities affect the knowledge required to pursue opportunities by focusing on the role of complementarities and multiple specificities of new capital resources, and the associated knowledge, used to perform activities. We use the framework to derive four propositions that can be used to empirically test the theory. Finally, we conclude our analysis and discuss the implications of our results for entrepreneurship research.

\section{OPPORTUNITIES FOR ENTREPRENEURIAL ACTION}

Despite the current focus on the concept of opportunity in entrepreneurship research it is fair to say that there is yet to emerge a consensus on its definition or meaning (Davidsson and Tonelli 2013, Hansen. Shrader, and Monllor 2011, Short et al. 2010). Most researchers agree about the importance of considering the nexus between enterprising individuals and situations in their environment for understanding entrepreneurial action, but the concept of opportunity has been used both as a reference to situations as objective reality external to the entrepreneur (Eckhardt and Shane 2003; Shane and Venkataraman 2000; Venkataraman 1997) as well as her subjective view of them (Ardichvili et al. 2003; Dimov 2011, Sarason et al 2006, Sarasvathyet al 2003). 
This difference also relates to whether opportunities are always profitable (Davidsson and Tonelli 2013) and if they are discovered or created (Alvarez and Barney 2007). Davidsson and Tonelli (2013) have suggested that due to this confusion the concept of opportunity should be abandoned in favor of the concept of a new venture idea, but Shane (2012) has proposed that a distinction should be made between opportunities as situations existing independent of the entrepreneur and business ideas that are entrepreneurs' interpretation of them including how they can be exploited. A distinction between opportunities and ideas makes it clear that entrepreneurs act upon interpretations that may turn out to have little correspondence with reality leading to adaptation or failure. Furthermore, opportunities can be created or discovered through entrepreneurial action and learning that started out with different objectives.

In this paper make a distinction between situations external to entrepreneurs and their interpretation of them. As Eckhardt and Shane (2003: 336) we define entrepreneurial opportunities as "situations in which new goods, services, raw materials, markets and organizing methods can be introduced through the formation of new means, ends, or means-ends relationships".- We emphasize the creative aspects of entrepreneurship (Hayek 1978) and phenomena that can be designed (Venkataraman, Sarasvaty, Dew, and Forster 2012) but exclude pure arbitrage (Kirzner 1973). However, we are not limiting ourselves to radical changes or fundamentally new means-ends relations but also including incremental changes and recombination of existing means for the same or different ends (Shane 2012).

By assuming that opportunities are both technologically and economically feasible we have in this paper a distinctive "taker" perspective, i.e. we are not much concerned with how these opportunities are created or by whom. Because of that we assume that the propensity for 
entrepreneurial action, i.e. who becomes an entrepreneur, depends on how well the already existing opportunity matches particular individuals or teams of individuals.

But what determines the match between an opportunity and an individual and produces entrepreneurial action? McMullen and Shepherd (2006) argue that the concept of uncertainty plays a key role as uncertainty in the context of action creates doubt that blocks or delays action, i.e. creates barriers to entry. In their conceptual model of entrepreneurial action they combine two streams of literature that use alternative conceptualization of uncertainty. First, entrepreneurial action is more likely for those who perceive such action to be less uncertain because they possess the knowledge necessary to both discover and exploit the opportunity in question. Second, entrepreneurial action is more likely for those who are motivated to bear more uncertainty. Taken together, prior knowledge is necessary for a potential entrepreneur to recognize that an external stimulus represents a potential opportunity and is also required for further assessing the technical and economic feasibility of an opportunity. Motivation will determine to what degree a person is attentive to such stimulus and if determines if its successful exploitation is desirable given the perceived uncertainty

In this paper we focus on the role of knowledge for entrepreneurial action. While acknowledging the importance of motivation we investigate who perceive the lowest uncertainty for entrepreneurial action following a particular environmental change, i.e. who perceive the lowest knowledge barriers to entry. We assume that knowledge and motivation are independent, i.e. that our results hold for a given level of motivation that is sufficient for entrepreneurial action to occur.

\section{ENTREPRENEURIAL ACTION AND ACTIVITY SYSTEMS}


Entrepreneurial action does not take place in a vacuum. Instead it is performed in an already existing structure of interlinked economic activities that are coordinated within firms, through business relationships, and market transactions. These activities require human and material resources including appropriate knowledge, experience and skills (Madhok 2002; Richardson 1972). Furthermore, innovations, which change some aspect of the economic structure, often do not stand alone, in the sense that to capture value entrepreneurs depend on complementary changes within an innovation business ecosystem (Adner and Kapoor 2010). Entrepreneurial action can therefore include the design of a new type of activity system or the improvement of an existing one. Due to its interconnectivity several adjustments are likely to be needed following any changes in the activity structure, especially following the design of a new type of activity system or a substantial change of an existing one. These adjustments are subsequent opportunities for entrepreneurial action.

A business model is a description of an activity system for doing business. It describes a set of activities, the resources and capabilities needed to perform them, the external actors involved, e.g. customer, suppliers, and partners, and how the activities are performed and organized. The architecture of the activity system describes how value is created in the system, determines what share of the value is appropriated by the focal business, and captures how the focal business is embedded in the overall economic structure (Zott and Amit 2010).

A priori, a business model reflects entrepreneurs' hypotheses about how value can be created and appropriated and can be used as a concept for framing a search and learning for an effective way of doing business (Chesbrough and Rosenbloom 2002, Teece 2010). It signifies a set of choices that need to be made by the entrepreneur that cannot be evaluated or performed without appropriate knowledge and skills. With a focus on action and activities that need to be performed 
the attention moves away from the idea of knowledge as assets or commodity, towards the idea of knowledge as the ability to leverage resources (Spender 1996). Thus, given appropriate knowledge and experience an individual will be more likely to pursue an entrepreneurial opportunity related to a particular activity system, prescribed by a business model, because she will be better able to leverage the resources used for performing the activities.

Having established our basic assumptions about the nature of entrepreneurial opportunity, entrepreneurial action and what promotes entrepreneurial action in an economy of interconnected activities we now turn to Lachmann's theory of capital and Menger's original work on goods of different order in order to analyze how a particular change in the structure of economic activities, namely the introduction of new type of capital resource, affects who will pursue subsequent entrepreneurial opportunities.

\section{CAPITAL STRUCTURE, KNOWLEDGE, AND ENTREPRENEURIAL ACTION}

The concept of a capital structure is a network structure of material means of production (Lachmann 1956/78) and as such it forms an activity structure that is the basis for entrepreneurial action. While some economists strive to homogenize the concept of capital through a common measurement unit (price, interest) in order to make it more suitable for quantitative economic analysis others stress its heterogeneous nature and how it shapes and is shaped by economic activities. 
One approach that stresses the heterogeneous nature of capital is the Austrian theory of capital that has its origins in the work of Carl Menger (1871/1976). ${ }^{1}$ Menger made a distinction between goods of different order based on how close or distant causal relationship they had with the satisfaction of wants or needs. Goods of the first order were consumer goods that could be "placed in direct causal connection with the satisfaction of human needs." (Menger 1871/1976: 57, italics added). Central to Menger's approach was his subjectivist perspective, leading him to stress individual knowledge and awareness of circumstances as being the basis for economic decisions rather than the actual circumstances themselves (Kirzner 1979). The value of consumer goods is therefore based on how well consumers perceive the goods to satisfy their needs, rather than the value of higher order goods, if any, needed for their production. Similarly, the value of higher order goods is based on the prospective value of the consumptions goods to whose production they are to be assigned (Menger 1871/1976: 150).

Goods having indirect causal relationship with the satisfaction of human needs are of second, third, or higher order. Complementary goods at higher order can be progressively transformed into goods of lower order until, finally, resulting in the satisfaction of human wants and needs. Goods of higher order thus represent the means of production, including the classical factors of land, labor, and capital, available to satisfy wants or needs. The whole economy is therefore composed of a complex structure of means-ends relationships where the placements of each higher order good is determined from the causal connection between a good and wants and needs, and from existing means of production. There is not a natural, given ranking of the order of any

\footnotetext{
${ }^{1}$ The Austrian theory of capital is not a homogenous school of ideas. The main difference that is of importance for this paper is to what degree it follows the subjective focus of Menger's approach and thus includes a role for entrepreneurial action. One stream can be discerned through the works of Böhm-Bawerk, Wicksell, Hicks and later neo-Austrians where the subjective focus is quickly eliminated. The second stream of works by Hayek, Lachmann,
} 
goods in this structure as the ranking is determined solely from a user and a factual production perspective.

Lachmann (1956/1978) develops Menger's theory of economic progress into a theory of capital structure. He defines capital as "the (heterogeneous) stock of material resources" and argues that capital resources are heterogeneous in use and cannot be combined in an arbitrary fashion. The purposes for which capital resources can be used depend on how they can be combined with other resources and activities. Certain modes of complementarity are technically feasible, but only a subset of them is economically viable. However, the economic significance of a capital resource is dependent on to what degree it is multiple specific, i.e. to what degree it can be used for several different purposes. For example, a technology platform that is used in a number of different types of products has higher multiple specificity than a platform used only for a particular type of products. Together, multiple specificity and complementarity provide the order of the capital structure, i.e. how capital resources and economic activities are structured to meet human needs, and flexibility for change.

The entrepreneur has a very explicit role in Lachmann's theory (Lachmann 1956/1978: 13-16, 20-24). Entrepreneurs form expectations about the future based on their subjective interpretation of past experience. Expectations are "provisional judgments to be confirmed by later experience, imperfect knowledge capable of being perfected." (p. 21). They are a part of ongoing process of acquiring knowledge about peoples' needs and the means to satisfy them in an economical way (p. 24). This ongoing process is reflected by changes in the capital structure, where entrepreneurs may choose to disintegrate existing capital combinations or create new ones based on their knowledge and expectations. 
Changes that are exogenous to an actor, such as disruptive changes in needs or technology, will make possible or even compel changes in the use of capital resources, which creates opportunities for the actor to take economic advantage of pursuing these changes. However, changes in the capital structure will themselves also create entrepreneurial opportunities by making some capital combinations less likely to be used after such a change, others more attractive, may even open up for new ones.

The ability to identify, and the willingness to take advantage of, the opportunities that these changes bring is based on the prior knowledge of available entrepreneurs as well as their motivation (McMullen and Shepherd 2006, Shane 2000). This means some individuals are more likely than others to take advantage these opportunities, and furthermore, for some individuals the likelihood of entrepreneurial action has increased because of the change, whereas for others the likelihood has decreased.

In other words, the capital structure is an ever-changing structure of means-ends relationships aiming to satisfy human needs. Capital resources are combined in an ordered albeit not a (fully) predictable manner based on the complementarities and multiple specificities of the resources themselves on the one hand, and the expectations, knowledge and actions of entrepreneurs on the other. In this sense the capital structure can be seen as an evolving structure of economic activities where entrepreneurs create, apply and distribute knowledge for leveraging material resources. Over time entrepreneurial action both shapes and is shaped by the capital structure in an endogenous manner where entrepreneurs are both makers and takers of opportunities for value creation and appropriation by creating new activity systems and improving existing ones. 
In the next section we spell out how Lachmann's theory can be used to predict how changes in the activity structure create new entrepreneurial opportunities and for whom. We focus on how available entrepreneurs are takers of opportunities following a specific change in the capital structure, i.e. who perceive the lowest knowledge barriers to entry following the introduction of a new capital resource.

\section{PURSUING ENTREPRENEURIAL OPPORTUNITIES FOLLOWING CHANGES IN CAPITAL STRUCTURE}

Lachmann's theory of capital brings together the buildings blocks that are needed for our purposes but there are a number of specific issues that need to be addressed. Most importantly Lachmann (1958/1978) is never very explicit about the relationship between knowledge and the capital structure. Lewin (1996) even argues that while the Austrian economists stress the importance of knowledge they tend to treat is as an exogenous variable never giving much attention to it as a phenomenon. In our case we need to explicitly specify how the complementarities and multiple specificities of capital resources affect the knowledge requirements for their development and use. To remedy this shortcoming we use Menger's (1871/1976) concept of goods of different order and based on that idea derive the idea of knowledge of different order.

Menger defined goods having indirect causal relationship with the satisfaction of human needs to be of second, third, or higher order. Goods at higher order are being progressively transformed into goods of lower order until, finally, resulting in the satisfaction of human needs. As long as these transformations are not automatic they require labor services by individuals who have the knowledge to carry them out. Drawing on this, knowledge can be seen as attributes of labor services at higher order that are required to produce a good of a lower order. Hence, as for goods 
of different order we can talk of knowledge of different order that is required for the progressive transformation of goods to meet the satisfaction of human needs.

Menger argued that two conditions needed to hold if a good is to have an indirect causal relationship with the satisfaction of needs. First, a command is needed of the complementarity goods of higher order required for its production, both in quality and quantity. Second, the qualities and quantities of the good itself have to fit the complementary goods needed for its transformation into a good of first order that directly satisfies human needs. As we are concerned with the creative aspect of entrepreneurship we are more interested in the complementary qualities of goods and how they are accomplished rather than their complementary quantities, i.e. how well their demand and supply is balanced.

The qualities of a good relate to its role in satisfying human needs, and the prospective value of meeting those needs. The accomplishment of these qualities is based on the complementary goods and labor services used for their production ${ }^{2}$. This means that not only is command required of complementary goods that are required to produce the good, but also a command of complementary knowledge at the same order. Similarly, the qualities of the good have to fit both the complementary goods and knowledge needed for its transformation into a good of first order.

We can rephrase this in terms of capital structure and activity systems. Given a point of departure from a good of a first order, i.e. a good directly meeting the satisfaction of human need, the production of that good is dependent on activities that leverage complementary capital resources at the second order. This repeats itself for any man-made capital resources used at the second or

\footnotetext{
${ }^{2}$ Here the concept of production includes both the development of a good and its delivery to a customer. The ability to develop a good is the ability to perceive and specify a delivery process (in some cases including manufacturing) of a good having certain qualities. The ability to deliver is the ability to implement the delivery process repeatedly.
} 
lower order, i.e. its production is based on both complementary capital resources and the complementary knowledge needed to leverage them.

Starting from a good of a first order is not they only perspective for viewing the capital structure. Depending on their multiple specificity capital resources need not to be confined to a single purpose but can be put into different use. This is both true of specific instances of a resource (e.g. a physical instance of a personal computer) and for a specific class of resources (personal computers in general). Furthermore, there may be alternative combinations of capital resources (activity systems) competing to produce a given good or capital resource. Each of these activity systems needs to be designed, implemented, and further adjusted through entrepreneurial action. The perceived uncertainty of the action, i.e. the propensity to act, is dependent on how knowledgeable the individual is about leveraging resources within that activity system.

Below we develop a model of the introduction of a capital resource using our framework of goods and knowledge of different order. For simplicity we limit ourselves to activity systems that only produce one a product or a service (good). Furthermore, we assume that there exists the possibility of making the production of the good more economical by introducing a capital resource that can be used as a substitute for one or more capital resources. We compare how the introduction of the capital resource changes knowledge barriers to entry assuming that lower barriers will increase the propensity for entrepreneurial action. A real life example roughly adhering to these assumptions is the introduction of web administration tools in the 90 s that will be used as an example to clarify the abstract model (Reference removed for review).

Let $\mathrm{M}, \mathrm{N}$ be integers, $2 \leq \mathrm{M}, \mathrm{N}$. Let $\mathrm{CR}_{\mathrm{i}}{ }^{\mathrm{N}}$ be a capital resource at the $\mathrm{Nth}$ order and $\mathrm{K}_{\mathrm{i}}^{\mathrm{N}}$ be the associated knowledge needed to leverage the resource for a particular purpose. Let us assume that 
before a particular point in time, $\mathrm{T}$, a set of $\mathrm{M}$ complementary capital resources and associated knowledge fields at the Nth order $\left(\mathrm{K}_{1}{ }^{\mathrm{N}} \mathrm{CR}_{1}{ }^{\mathrm{N}}, \mathrm{K}_{2}{ }^{\mathrm{N}} \mathrm{CR}_{2}{ }^{\mathrm{N}}, \ldots, \mathrm{K}_{\mathrm{M}}{ }^{\mathrm{N}} \mathrm{CR}_{\mathrm{M}}{ }^{\mathrm{N}}\right)$ are needed to produce a class of goods of the N-1 order $\left(\mathrm{G}^{\mathrm{N}-1}\right)$. By a class of goods we mean a category of goods that meet certain ends, but may differ in how well they do so. As $\mathrm{N} \geq 2$ the goods at the $\mathrm{N}-1$ order may be goods at the first order that directly satisfies human needs or wants, or of higher order that does so indirectly through its complementary with goods at the same or lower order.

Let us assume that a new capital resource at the Nth-order, termed the capital resource $\mathrm{CR}_{\mathrm{M}+1}{ }^{\mathrm{N}}$, becomes available at time T', T'>T. The capital resource $\mathrm{CR}_{\mathrm{M}+1}{ }^{\mathrm{N}}$ can be used to replace the $\mathrm{CR}_{1}{ }^{\mathrm{N}}, \mathrm{CR}_{2}{ }^{\mathrm{N}}, \ldots, \mathrm{CR}_{\mathrm{j}}{ }^{\mathrm{N}}, \mathrm{j}$ integer $\geq 1$. This means that when using $\mathrm{CR}_{\mathrm{M}+1}{ }^{\mathrm{N}}$ to produce $\mathrm{G}^{\mathrm{N}-1}$ the labor services from individuals mastering knowledge fields $\mathrm{K}_{1}{ }^{\mathrm{N}}, \mathrm{K}_{2}{ }^{\mathrm{N}}, \ldots, \mathrm{K}_{\mathrm{j}}{ }^{\mathrm{N}}$ are not required. Only services based $\mathrm{K}_{\mathrm{j}+1}{ }^{\mathrm{N}}, \mathrm{K}_{\mathrm{j}+2}{ }^{\mathrm{N}}, \ldots, \mathrm{K}_{\mathrm{M}+1}{ }^{\mathrm{N}}$. Furthermore, in order to produce $\mathrm{CR}_{\mathrm{M}+1}{ }^{\mathrm{N}}$ a set of $\mathrm{L}$ complementary capital resources and associated knowledge fields at the $\mathrm{N}+1$ th order $\left(\mathrm{K}_{1}{ }^{\mathrm{N}+1}\right.$ $\mathrm{CR}_{1}{ }^{\mathrm{N}+1}, \mathrm{~K}_{2}{ }^{\mathrm{N}+1} \mathrm{CR}_{2}{ }^{\mathrm{N}+1}, \ldots, \mathrm{K}_{\mathrm{L}}{ }^{\mathrm{N}+1} \mathrm{CR}_{\mathrm{L}}{ }^{\mathrm{N}+1}$ ) are needed. For brevity we will term knowledge fields $\mathrm{K}_{1}{ }^{\mathrm{N}}, \mathrm{K}_{2}{ }^{\mathrm{N}}, \ldots, \mathrm{K}_{\mathrm{j}}{ }^{\mathrm{N}}$ as the abstracted knowledge fields, the knowledge fields $\mathrm{K}_{\mathrm{j}+1}{ }^{\mathrm{N}}, \mathrm{K}_{\mathrm{j}+2}{ }^{\mathrm{N}}, \ldots, \mathrm{K}_{\mathrm{M}}{ }^{\mathrm{N}}$ as the non-abstracted knowledge fields, $\mathrm{K}_{\mathrm{M}+1}{ }^{\mathrm{N}}$ as the new knowledge field for use, and $\mathrm{K}_{1}{ }^{\mathrm{N}+1}, \mathrm{~K}_{2}{ }^{\mathrm{N}+1}$, $\ldots, \mathrm{K}_{\mathrm{L}}{ }^{\mathrm{N}}$ as the new knowledge field for production.

In our example the introduction of web administration software (a new capital resource) offered to replace the use of various programming tools used to make custom-made scripts for database access and display control. The level of computer programming knowledge required for creating and managing web system (abstracted knowledge fields) was greatly reduced by this change and instead knowledge of web administration system was required (new knowledge field of use). However, the need for knowledge of graphic design (non-abstracted knowledge field) and the tools used for it stayed the same. 
Two new opportunities are created by this change. First, there is the opportunity to produce $\mathrm{G}^{\mathrm{N}-1}$ using the new capital resource (the primary opportunity). Second, there is the opportunity to produce a capital resource in the same class as $\mathrm{CR}_{\mathrm{M}+1}{ }^{\mathrm{N}}$ (the secondary opportunity). We now look at each of these opportunities and investigate how knowledge barriers to entry are affected by complementarity and multiple specificity of the new capital resource.

Complementarity of capital resources is a property that depends on that they are used jointly for a given purpose (Lachmann 1977: 200). One aspects of complementarity is the physical compatibility of the material resources, e.g. the staples have fit the stapler and the computer has to be connected to the printer. Another aspects of complementarity is the compatibility and consistency of the associated knowledge, i.e. the knowledge for leveraging a resource is taking into account the complementary resources and how they are being used for a particular purpose in that combination. For example, the knowledge for using specialized software for graphical design of an advertisement in an exclusive high quality printed magazine is taking into account that the design needs to be color printed in high resolution.

Multiple specificity of a capital resource implies that it can be used, up to a certain limit, for different purposes and be combined with different capital resources. Even if the physical characteristics of the capital resources stay the same the associated knowledge may differ depending on the requirements for complementing other resources and for what purposes the resource combination is used. For example, the knowledge required to use a word processor to write computer programs that transformed into machine code using a compiler is different than the knowledge needed to use a word processor to write a sales letter and print it using a printer. 
In Lachmann's theory complementarity and multiple specificity of capital resources account for stability and flexibility of the capital structure respectively. If the purpose for using a particular resource combination changes, or if the combination of resources used for a specific purpose changes, complementarities will change and that will affect the knowledge required for leveraging each capital resource in the new context. These changes in knowledge requirements can be anticipated using our prior knowledge and experiences, but these expectations are based on "imperfect knowledge to be tested and improved by later experience" (Lachmann 1978: 23). This means that identifying the need, or opportunity, for adjustment is dependent on prior knowledge and experience. It also means that adapting to a change takes time and learning. Finally, it means that failures are possible. Thus, changes in the capital structure have created uncertainty, but how this uncertainty is perceived depends on prior knowledge and experience.

Going back to our model we find that in the case of the primary opportunity the purpose has stayed the same but the combination of capital resources have changed leading to new complementarities and uncertainties about the knowledge requirements for leveraging the resources in this new context. In the case of the secondary opportunity a new purpose has been created, i.e. the production of a new class of good (capital resource). Given that this is a new good one can expect that complementarities between capital resources are not fully established and that knowledge for leveraging resources for that particular purpose is still imperfect. The question is now under what conditions knowledge barriers to pursue these opportunities are lowered and for whom.

An important condition affect knowledge barriers is the mutual dependencies between associated knowledge fields, i.e. the decomposability of the knowledge structure (Simon 1996). Mutual dependencies can range from weak to strong. When mutual dependencies are weak, i.e. the 
knowledge structure is highly decomposable, a need for adaptation and learning in one field does not call for associated adaptation and learning in another field. When mutual dependencies are strong, i.e. the knowledge structure is tightly coupled, a need for adaption and learning in one field calls for adaptation and learning in all knowledge fields.

When we look at the primary opportunity without considering the decomposability of the knowledge structure we expect individuals (teams) endowed with knowledge within the nonabstracted fields and the new field for use to experience the lowest barriers to entry. However, if we assume strong mutual dependencies between the abstracted knowledge fields and the new knowledge fields for use a different picture emerges. In that case it is difficult to develop the knowledge needed to leverage the new capital resource without prior knowledge within the abstracted knowledge fields. The substitution provided by the new capital resources is incomplete, as it is not reducing the need for using the abstracted knowledge fields. This leads us to our first set of proposition:

Proposition 1: When mutual dependencies between the abstracted knowledge fields and the new knew knowledge field for use are low, individuals (teams) having prior knowledge within the non-abstracted knowledge fields and the new knowledge field for use perceive the least uncertainty related to pursing the primary opportunity.

Proposition 2: When mutual dependencies between the abstracted knowledge fields and the new knew knowledge field for use are high, individuals (teams) having prior knowledge within the non-abstracted knowledge fields, abstracted knowledge fields, and the new knowledge field for use perceive the least uncertainty related to pursing the primary opportunity.

Concerning our example for the introduction of web administration software we would expect, based the above propositions, that given the web designers using web administration software did not require the programming skills needed to build them (weak dependencies), individuals 
(teams) having prior knowledge in graphical design would experience the lowest knowledge barrier to entry into web design. However, if the use of web administration software still required the use of programming skills, individuals (teams) with knowledge both in graphical design and web programming would experience the lowest knowledge entry barriers.

When we look at the secondary opportunity without considering the decomposability of the knowledge structure we expect individuals (teams) with prior knowledge within the new knowledge fields for production to experience the lowest knowledge barriers to entry. However, here the situation changes when we assume strong mutual dependencies between the abstracted knowledge fields and the new knowledge fields for production. In that case the knowledge required to produce the new capital resource at the Nth order is highly coupled to the knowledge it replaced at the same order. In fact, it might even use same, or similar capital resources. Hence, individuals (teams) with prior knowledge within the abstracted knowledge fields experience and individuals (teams) with prior knowledge within the new knowledge field for production experience the lowest knowledge barrier to entry. This leads us to the second and final set of propositions:

Proposition 3: When mutual dependencies between the abstracted knowledge fields and the new knew knowledge fields for production are low, individuals (teams) having prior knowledge within the new knowledge fields for production perceive the least uncertainty related to pursing the secondary opportunity.

Proposition 4: When mutual dependencies between the abstracted knowledge fields and the new knew knowledge fields for production are high, individuals (teams) having prior knowledge within the abstracted knowledge fields or within the new knowledge fields for production perceive the least uncertainty related to pursing the primary opportunity. 
For our example of the introduction of web administration software we would expect, based on the above proposition, that if the production of web administration software were based on the same programming skills that were previously used to design web pages, individuals (teams) with those programming skills, or other related skills, would experience the lowest knowledge barriers to entry for producing web administration software. However, if the production were based on other skills that had little relation to the skills used previously individuals (teams) with those other skills would experience the lowest knowledge barrier to entry.

\section{DISCUSSION AND CONCLUSION}

The aim of this paper is to contribute to our understanding of the endogenous nature of entrepreneurship. More precisely, we ask why some people, but not others, pursue entrepreneurial opportunities following changes in an activity system. We use Lachmann's theory of capital to develop a theoretical framework for analyzing how changes in the structure of activities affects who perceive the least uncertainty for entrepreneurial action.

We use the framework to develop four propositions about for whom entrepreneurial opportunities are created following the introduction of a new capital resource. We can interpret the change as a new business model built around a new combination of capital resources used for a given purpose. This business model could be pursued by a separate activity system (a start-up) or be pursued in combination with other business models in an existing activity system (firm). The ability to recognize this opportunity and to have low perceived uncertainty in pursing it is based on particular knowledge fields and those individuals, or team of individuals, that are endowed with these knowledge fields have higher propensity for entrepreneurial action. 
Furthermore, the change augments the economic activity structure by providing opportunities for a new business model around a new purpose, namely to produce the new capital resource. Initially, this capital resource may only be intended only for the purpose it was built, but later on it may increase its multiple specificity, i.e. be used for a number of different purposes. Also, the new capital resource might have been developed for other purposes already and its introduction into the specific context investigated was an example of its multiple specificity. In any case, this secondary opportunity and its possible interconnectivity to other elements in the economic structure illustrate the endogenous nature of entrepreneurial opportunities.

In this paper we have laid some groundwork for understanding how entrepreneurial activity is shaping and is shaped by changes in the economic structure. We encourage further development of our framework and empirical studies that investigate how changes in activity systems create new opportunities and for whom. We also believe our approach is not only helpful for understanding entrepreneurial action where entrepreneurs are takers of opportunities, but also action where entrepreneurs are makers of opportunities.

We argue that more research along these lines is important for entrepreneurship research for several reasons. First, it may be able to better predict Schumpeterian swarming following changes in an activity system, i.e. the rate and direction of imitation following an innovation (Schumpeter 1934). Not only is this phenomenon of interest for researchers and policy makers, but also for entrepreneurs as designers of new business models (Zott and Amit 2010), who are interested in the competitive advantage of the focal firm, and business managers who want to remove bottlenecks their innovation ecosystems (Adner and Kapoor 2009). Second, as our approach is based on the general notion of goods and knowledge of higher order we believe it has a very general applicability in terms of activity system changes. To date we have used it for empirically 
studying the effects of the introduction of new software tools (Reference removed for review) but we believe it can be extended to include other kinds of capital resources, both tangible and intangible, such as platform technologies, manufacturing methods, business development methods, etc. 


\section{REFERENCES}

Adner, R. and Kapoor, R. 2010. Value creation in innovation ecosystems: how the structure of technological interdependence affects firm performance in new technology generations. Strategic Management Journal, 31: 306-333.

Alvarez, S. A., \& Barney, J. B. 2007. Discovery and creation: alternative theories of entrepreneurial action. Strategic Entrepreneurship Journal, 1:11-26.

Ardichvili, A., Cardozo, R., \& Ray, S. 2003. A theory of entrepreneurial opportunity identification and development. Journal of Business Venturing, 18: 105-123.

Barreto, I. 2012. Solving the entrepreneurial puzzle: the role of entrepreneurial interpretation in opportunity formation and related processes. Journal of Management Studies, 49(2): 356-380.

Brockhaus, R. H., \& Horwitz, P. S. 1986. The psychology of the entrepreneur. In D. L. Sexton \& R. W. Smilor (Eds.), The Art and Science of Entrepreneurship (25-48). Cambridge, MA: Ballinger.

Buenstorf, G. 2007. Creation and pursuit of entrepreneurial opportunities: an evolutionary economics perspective. Small Business Economics, 28: 323-337.

Chesbrough, H.W., \& Rosenbloom, R.S. 2002. The role of the business model in capturing value from innovation: Evidence from Xerox Corporation's technology spinoff companies. Industrial and Corporate Change, 11(3): 529-555.

Choi, Y. R., \& Shepherd, D. A. 2004. Entrepreneurs' decisions to exploit opportunities. Journal of Management, 30: 377-395.

Davidsson, P. \& Tonelli, M. 2013. Killing our darling: why we need to let go of the entrepreneurial opportunity construct. In Davidsson, Per (Ed.) Conference Proceedings : Australia Centre for Entrepreneurship (ACE) Research Exchange Conference 2013, Australia Centre for En- trepreneurship, Queensland University of Technology, Brisbane, QLD.

Dimov, D. 2007. From opportunity insight to opportunity inention: the importance of personsituation learning match. Entrepreneurship Theory and Practice, 5:561-583.

Eckhardt, J. T., \& Shane, S. A. 2003. Opportunities and Entrepreneurship. Journal of Management, 29(3): 333-349. 
Gaglio, C. M. 2004. The role of mental simulations and counterfactual thinking in the opportunity identification process. Entrepreneurship theory and practice, Winter: 533552.

Garrison, R. W. 1990. Austrian capital theory: the early controversies. In B. J. Caldwell (Ed.), Carl Menger and his Legacy in Economics. Durham, NC: Duke University Press.

Hansen, D.J., Shrader, R., \& Monllor, J. 2011. Defragmenting defnitions of entrepreneurial opportunity. Journal of Small Business Management, 49(2): 283-304.

Hayek, F.A. 1978. Competition as a discovery procedure. In F.A. Hayek, New Studies in Philosophy, Politics, Economics and the History of Ideas (179-190). Chicago: University of Chicago Press.

Haynie, J. M., Shepherd, D. A., \& McMullen, J. S. 2009. An opportunity for me? The role of resources in opportunity evaluation decisions. Journal of Management Studies, 46: 337389.

Kirzner, I. M. 1973. Competition and Entrepreneurship. Chicago: The University of Chicago Press.

Kirzner, I. M. 1979. The Entrepreneurial Role in Menger's System. In I. M. Kirzner (Ed.), Perception, opportunity, and profit : studies in the theory of entrepreneurship (53-75). Chicago: Univ. of Chicago Press.

Lachmann, L. 1956/1978. Capital and Its Structure. Kansas City: Sheed Andrews and McMeel. Lewin, P. 1996. Time, change and complexity: Ludwig M. Lachmann's contributions to the theory of capital. Advances in Austrian Economics, 3: 107-165.

Madhok, A. 2002. Reassessing the fundamentals and beyond: Ronald Coase, the transaction cost and resource-based theories of the firm and the institutional structure of production. Strategic Management Journal, 23, 535-550.

McMullen, J. S., \& Shepherd, D. A. 2006. Entrepreneurial action and the role of uncertainty in the theory of the entrepreneur. Academy of Management Review, 31(1): 132-152.

Menger, C. 1871/1976. Principles of Economics. New York: New York University Press.

Michell, R. K., Michell, J. R., \& Smith, J. B. 2008. Inside opportunity formation: enterprise failure, cognition, and the creation of opportunities. Strategic Entrepreneurship Journal, 2: $225-242$.

Richardson, G.B. 1972. The organization of industry. The Economic Journal, 82: 883-896. 
Rosenberg, N. 1976. Perspectives on Technology. Cambridge: Cambridge University Press.

Rosenberg, N. 1982. Inside the Black Box: Technology and Economics. Cambridge: Cambridge University Press.

Sarason, Y., Dean, T., \& Dillard, J. F. 2006. Entrepreneurship as the nexus of individual and opportunity: a structuration view. Journal of Business Venturing, 21(3): 286-305.

Sarasvathy, S. D., Drew, N., Velamuri, S. R., \& Venkataraman, S. 2003. Three views of entrepreneurial opportunity. In Z. J. Acs \& D. Audretsch (Eds.), Handbook of Entrepreneurship Research: An Interdisciplinary Survey and Introduction (141-160). Dordrecht, NL: Kluwer.

Schumpeter, J. A. 1934. The Theory of Economic Development. Cambridge, MA: Harvard University Press.

Shane, S. 2000. Prior knowledge and the discovery of entrepreneurial opportunities. Organization Science, 11(4), 448-469.

Shane, S. 2012. Reflections on the 2010 AMR decade award: Delivering on the promise of entrepreneurship as a field of research. Academy of Management Review, 37(1): 10-20.

Shane, S., \& Venkataraman, S. 2000. The Promise of Entrepreneurship as a Field of Research. Academy of Management Review, 25(1): 217-226.

Shepherd, D. A., McMullen, J. S., \& Jennings, P. D. 2007. The formation of opportunity beliefs: overcoming ignorance and reducing doubt. Strategic Entrepreneurship Journal, 1: 7595.

Short, J. C., Ketchen, D. J., Shook, C. L., \& Ireland, R. D. 2010. The concept of "opportunity" in entrepreneurship research: past accomplishments and future challenges. Journal of Management, 36: 40-65.

Simon, H. 1996. The sciences of the artificial. Cambridge: MIT Press.

Spender, J.-C. 1996. Making knowledge the basis of a dynamic theory of the firm. Strategic Management Journal, 17: 45-62.

Teece, D. J. 2010. Business models, business strategy and innovation. Long Range Planning, 43: $172-194$

Venkataraman, S., Sarasvathy, S.D., Dew, N., and Forster, W.R. 2012. Reflections on the 2010 AMR decade award: Whither the promise? Moving forward with entrepreneurship as a science of the artificial. Academy of Management Review, 37(1): 21-33. 
Submission \#16318

Zott, C. and Amit, R. 2010. Business model design: an activity system perspective. Long Range Planning, 43: 216-226.

Zott, C., Amit, R., and Massa, L. 2011. The business model: recent developments and future research. Journal of Management, 37(4): 1019-1042. 